of this technique for the ready production and maintenance of virus-free canes are obvious. J. Chambers

Scottish Horticultural Research Institute, Mylnefield, Invergowrie, By Dundee. Dec. 3.

1 Thung, T. H., Meded. Dir. Tuinb., 15, 714 (1952).

${ }^{2}$ Cadman, C. H., Ann. App. Biol., 38, 801 (1951).

${ }^{3}$ Cadman, C. H., Ann. App. Biol., 39, 501 (1952).

\section{Cuticles of Erupted Teeth}

IT is generally agreed that Nasmyth's membrane, which is present on the enamel surface of recently erupted teeth, is composed of an outer cellular and an inner structureless layer, and that shortly after eruption the cells are lost due to degeneration and masticatory trauma. Whether or not the inner structureless layer remains on the surface is a matter of controversy, but it may be inferred from recent papers that it does remain throughout life $\mathrm{e}^{1-3}$. This, however, is difficult to envisage in view of the findings of Scott et al. ${ }^{4}$ and Scott ${ }^{5}$, who have demonstrated the wear which takes place continually on the enamel surface of erupted teeth, although it is true that these authors do speak of a 'cuticle'.

On the other hand, Manly ${ }^{8}$, Vallotton ${ }^{7}$ and Atkinson $^{8}$ have reported the formation of an amorphous membranous deposit on the enamel surface of erupted teeth. This suggests the possibility of confusion between two membranes of differing origin.

In agreement with Atkinson's findings an amorphous cuticle, resembling in appearance the inner structureless layer of Nasmyth's membrane, has been recovered from areas of enamel attrition as well as from the remaining enamel surface. However, on close examination two differences were observed. First, only the inner layer of Nasmyth's membrane exhibits interference phenomena, and secondly, this layer is marked by outcrops of the enamel prism ends grouped in lines typical of the unworn enamel surface, whereas the cuticle present on older emupted teeth is marked either faintly or not at all. Furthermore, the two membranes differ chemically. The cuticle of erupted teeth is more stable in strong acid at room temperature, and at boiling point it forms 'humin'. This, together with the positive reactions obtained with protein and carbohydrate tests, may indicate that the cuticle contains both these substances in combination. The nature of this combination is indicated by metachromatic staining with toluidine blue and by a positive periodic acid - Schiff reaction, suggesting that the cuticle may contain a mucoprotein. Lipoid is also demonstrable using sudan $B$.

In consequence of these observations, a series of experiments was carried out using the crown of a 'normal' caries-free tooth extracted from an adult. After removal of the cuticle by immersion in acid the tooth was fitted to a partial denture. This denture was worn in the mouth for periods varying from 7 to 63 days. At the end of each period a cuticle, which in all respects resembled the naturally occurring structure on the enamel of adult erupted teeth, was removed from the crown surface. It is interesting to note that this occurred in spite of the fact that some features of a vital tooth, such as those concerned with enamel permeability, were absent. Atkinson and Prophet suggested that substances from the saliva might be involved in the formation of 'crack lamellæ'.
In the present investigation the naturally occurring cuticle is found to be connected with such lamellæ, which show the same properties chemically (in contrast with developmenta] lamellæ obtained from unerupted teeth).

From these observations it appears evident that what in the past has been identified on adult erupted teeth as the inner structureless layer of Nasmyth's membrane has, in fact, been a cuticle formed, and capable of re-formation, after eruption. Bacteria are not found to be constituents of the cuticle.

E. P. TURNER

Turner Dental School, University of Manchester. Jan. 15.

1 Darling, A. I., Proc. Roy. Soc. Med., 36, 499 (1943).

${ }^{2}$ de Fazio, E., La Stomatologia, 8, 245 (1947).

${ }^{3}$ Hodson, J. J., Brit. Dent. J., 87, 167 (1949). - Scott, D. B., and Wyckoff, R. W. G., J. Amer. Dent. Assoc., 39, 275

${ }^{5}$ Scott, D. B., Oral Surg. 5, 638 (1952).

- Manly, R. S., J. Dent. Res., 22, 479 (1943).

7 Vallotton, C. F., J. Dent. Res., 24, 161 (1945).

atkinson, H. F., thesis, University of Manchester (1950).

-Atkinson, H. F., and Prophet, A. S., Brit. Dent. J., 95, 60 (1953).

\section{Divergence in Helical Polypeptide Chains and in Phyllotaxis}

IN the $\alpha$-form of synthetic polypeptide chains (poly-l-alanine, poly- $\gamma$-methyl-l-glutamate) divergences of the individual amino-acid residues of 5/18, $8 / 29$ or $13 / 47$ corresponding to helix periods of $27 \mathrm{~A}$., $43 \mathrm{~A}$., or $70.4 \mathrm{~A}$., are discussed ${ }^{1,2}$. The numerators of these figures remind one of the divergences of phyllotaxis, where 5/13,8/21 and $13 / 34$ are members of the

$$
\text { phyllotaxis sequence } \frac{1}{2} \frac{1}{3} \frac{2}{5} \frac{3}{8} \frac{5}{13} \frac{8}{21} \frac{13}{34} \ldots
$$

In this sequence the numerator and the denominator of every member is the sum of those of the two preceding members. Since this regularity applies also to the divergences discussed for the $\alpha$-polypeptide helices, an extrapolation to hypothetical lower members of a similar sequence is possible. As a result the following

$$
\text { helix sequence }\left(\frac{1}{3} \frac{1}{4} \frac{2}{7} \frac{3}{11}\right) \frac{5}{18} \frac{8}{29} \frac{13}{47} \ldots
$$

is obtained. It is possible that higher members of this sequence might have a practical significance for polypeptide helices with long-range periods higher than $70 \cdot 4 \mathrm{~A}$. The lower extrapolated members, between brackets, have probably no real meaning; they are only mentioned to show that the discussed divergences are members of a very striking sequence, comparable to that in phyllotaxis.

The similarity is certainly due to the same geometrical cause, that is, as dense as possible an arrangement of identical objects along a helix. In the case of phyllotaxis these objects are the protuberances of the young leaves on the growing point in a bud, and in that of the polypeptide helices the amino-acid residues in the crystal lattice.

Department of General Botany,

A. Frex-Wyssting

Swiss Federal Institute of Technology Zurich. Jan. 7.

\footnotetext{
${ }^{1}$ Bamford, C. H., Brown, L., Elliott, A., Hanby, W. E., and Trotter, I. F., Nature, 178, 27 (1954).

${ }^{2}$ Pauling, L., and Corey, R. B., Nature, 171, 59 (1953), find 12.5/45 which is nearly $13 / 47$.
} 